\section{Thorax: the Cappuccino years}

\author{
Andrew Bush, ${ }^{1}$ lan D Pavord ${ }^{2}$
}

We are now about half way through our term of office (unless we are prematurely fired for terminal misbehaviour); here we review where we are, and where we are going, and have the first instalment of the showcase of some of our best articles from last year. We have maintained our second position with an improved impact factor (6.84) over 2011, we continue to attract very high quality manuscripts, and handling times have come down (all good news). We owe these achievements to our associate editors and editorial board, the reviewers, and especially those who have submitted such great manuscripts. An especially large bouquet to the editorial staff, in particular Renuka Patel for her work on Hot Topics and marketing, Bryony Skinner, who has stepped magnificently into the breach, Allison Lang and our unsung heroine Sarah Szatkowski, who keeps us sane when ScholarOne is driving us to Prozac or haloperidol or both. Don't leave us! We acknowledge we need to speed up further, and get the impact factor higher -both are a work in progress. However, average time from submission to first decision for all manuscripts is less than 30 days, and accepted manuscripts appear on-line in an average of 25 days. We have had out first randomised controlled trial protocol to review for consideration for fast-track publication when the study is completed-an offer which does not depend on the result being positiveinvestigators please note. Hot off the Breath continues to generate controversy - totally drug resistant tuberculosis (TB) and the roaring PANTHER being cases in point. We have had two themed issues (North American, to coincide with American Thoracic Society and cystic fibrosis (CF), to coincide with the US CF Foundation annual meeting). In 2013, we will have a Tuberculosis themed issue for World TB day (March 24th) and plan a Pneumonia themed issue for World

\footnotetext{
'Department of Paediatric Respiratory Medicine, Imperial College \& Royal Brompton \& Harefield NHS Foundation Trust, London, UK; ${ }^{2}$ Department of Respiratory Medicine, Allergy and Thoracic Surgery, Institute for Lung Health, Glenfield Hospital, University Hospitals of Leicester NHS Trust, Leicester, UK
}

Correspondence to Professor Andrew Bush, Department of Paediatric Respiratory Medicine, Imperial College \& Royal Brompton \& Harefield NHS Q6 Foundation Trust, London, UK; A.Bush@rbht.nhs.uk
Pneumonia day (November 12th). We are continuing to use Podcasts and are keen to explore better use of electronic media - suggestions (and help for the terminally e-illiterate) are welcome. We would also welcome ideas for further themed issues.

We have been fortunate in publishing some great manuscripts in 2012. We have chosen four areas to highlight, and, in the Olympic Year, we have awarded gold, silver and bronze in each category. There is no overall winner; can you compare Michelangelo's David with Beethoven's ninth symphony? Apologies if your manuscript is missed or you think you should have won the prize; the rules were that the editors' own manuscripts were automatically disqualified, and the umpires' verdict is both final and arbitrary. Better luck next year, keep the great manuscripts coming. This month we showcase Paediatric and Adult Thoracic Medicine; next month, epidemiology and basic science.

\section{PAEDIATRIC LUNG DISEASE}

The main themes have been asthma and CF, respectively the most common problem in childhood and the area where there is the most game-changing research going on. Asthma is much more than reaching for the prescription pad. We can and should do our best to improve the environment. Tobacco (again!) is the lead culprit, with paternal as well as maternal tobacco abuse being shown to be important by the ISAAC programme. ${ }^{1}$ We need to look beyond the home; the COPSAC group reported the association between short-term exposure to air pollution and hospital admissions for asthma. ${ }^{2}$ The strong relationship in infants is a puzzle, given one would expect them to be outside the home less than older children, but maybe this reflects the extreme vulnerability of the developing lung. School air quality was also highlighted as an area for improvement. ${ }^{3}$ Allergens are another perennial theme, and a long-term prospective study from the Isle of Wight demonstrated that an intensive allergen avoidance programme starting from birth reduced the risk of asthma onset in genetically predisposed individuals ${ }^{4}$; this is the Bronze medal manuscript, a whisker behind the silver medal position, for a superb, longhaul effort. A randomised, double-blind, placebo controlled trial of allergen reduction using a commercially available device aiming to reduce allergen exposure to producing nocturnal, temperature controlled laminar airflow during sleep showed improved quality of life and reduced systemic inflammation, but unfortunately no effect on exacerbations. ${ }^{5}$ Of course pharmacotherapy is important, and we debated the hot topic of whether continuous or intermittent inhaled corticosteroids were correct for children with mild asthma. ${ }^{6} 7$ However, whatever the outcome of the debate in the rarefied atmosphere of the hospital clinic, it is likely in practice that families will do their own thing in real life! One issue is that you cannot treat that which is not perceived, and we also published a great manuscript showing that, in inner city asthmatic children, perception of asthma is poor but can be improved by appropriate feedback, at least in the short-term ${ }^{8}$; this is accompanied by improved adherence to therapy. This manuscript wins the Silver medal in recognition of the difficulty of doing research in such a challenging environment. Finally, for connoisseurs of public fist-fights, two papers about monitoring severe asthma ${ }^{9}{ }^{10}$ triggered LeicesterLondon internecine warfare in the editorial columns ${ }^{11} 12$ and correspondence. ${ }^{13} 14$ Judge between the editors: is induced sputum useful in childhood severe, therapy-resistant asthma, and if not, why not?

CF was the second major topic. Three manuscripts covered CF new-born screening (NBS) and outcomes. ${ }^{15-17}$ Strategies of NBS were compared in a prospective study, ${ }^{15}$ especially to inform countries where DNA screening may not be acceptable, and reassuringly, all strategies performed well. Australian-UK controversy is heating up nicely ahead of the Ashes series, in terms of outcomes; the Australian group reported deterioration in structural lung disease with worsening infection and inflammation in their NBS group $^{16}$; the UK London collaboration resolved the controversy about whether CF NBS babies have impaired lung function shortly after diagnosis (they do), ${ }^{17}$ but their follow-up data, so far only presented in abstract, may tell a different story. Don your helmet, watch this space and be ready for the sledging and shortpitched bowling! Space precludes reviewing a number of excellent CF randomised controlled trials, but we highlight two areas where what was thought to be simple has become complex. The first is diagnosis-as medical students we were taught that the sweat test was the be-all and end-all of diagnosis, but we are now 
finding that it may be normal in milder or single-organ atypical cases; however, pace Oscar Wilde, in this case the UK and North America have the same language in common, and largely agree on diagnostic criteria. ${ }^{18} 19$ Second, we were taught that CF was a polymicrobial disease; now molecular techniques have taught us that the CF airway is teeming with multiple organisms, and the community stays largely stable in a given individual, despite antibiotic therapy. ${ }^{20}$ In an accompanying editorial, LiPuma charts a path for the confused, as well as re-assuringly demonstrating to the intellectually challenged that even the serious scientists are struggling with the implications of these novel data. $^{21}$

Finally, Thorax was not a two horse show in 2012. Important manuscripts included guidelines on the management of neuromuscular disease in children, ${ }^{22} 23$ which gives a comprehensive overview of how to look after a group of conditions which are becoming of increasing importance in adult practice; a randomised controlled trial of oral antibiotics in chronic wet cough $^{24}$ (showing our forebears were not as stupid as we thought! Keep doing the same thing long enough and you will be back in fashion); and a further testing of the special relationship in a USA-UK debate about what makes a diagnosis of primary ciliary dyskinesia ${ }^{25-28}$ - genes versus not the environment but function - decide for yourself. The gold medal winner is in this category; we all know (or should know) that survivors of very preterm birth and intensive neonatal interventions have long term respiratory morbidity and premature airflow obstruction. This manuscript, based on the Avon Longitudinal Study of Parents and Children (ALSPAC) cohort showed that late pre-term (33-34 weeks gestation) infants have just as severe lung function decrements as 25 week gestation babies, ${ }^{29}$ and there are a whole lot more pretermers. For sure there was some improvement by the late teenage years in the late pre-term group, but this has considerable importance for adult practice; do not be complacent just because the baby was 'a bit early'!

\section{ADULT LUNG DISEASE}

There have been strong contributions in lung cancer, idiopathic pulmonary fibrosis (IPF) and obstructive lung disease. Screening for lung cancer was very much the topic of the year. We are more sceptical of the benefits of this approach than many and are keen that we do not commit ourselves to an expensive screening protocol without being absolutely sure that it is efficacious, feasible and acceptable to participants. Saghir et $a l^{30}$ raised some concerns about efficacy in a preliminary report from the Danish Lung Cancer Screening Trial, suggesting that the main impact of screening was bringing forward early disease rather than a reduction in mortality. The concept that some cancers may be innocent bystanders rather than active players in the development of morbidity and death is important, and when Thoracic Surgeons start talking about it, ${ }^{31} 32$ we should take note. Attitudes to participation in lung cancer screening clearly depend on the likely benefits but understanding other factors is important in a population who might be nihilistic about health promotion initiatives. Patel et $a l^{33}$ found that the screening tests were acceptable to most but that the factors contributing to the decision to participate were complex and probably difficult to modify. Might it be better to focus more on increasing public awareness of symptoms and promoting earlier diagnosis? Some progress is being made as resection rates are increasing in the $\mathrm{UK}^{34}$ but there is still along way to go. Simon et $a l^{35}$ assessed public awareness of symptoms using a new assessment tool and found that it was low, particularly in the most high risk groups. Athey et $a l^{36}$ recognised that increasing awareness of lung cancer might be a way of tackling the high lung cancer mortality in Doncaster and developed a multi-faceted intervention to improve public awareness of symptoms. The initiative was informed by local qualitative research and was highly imaginative, including coughing phone boxes, billboards and illustrated beer mats. It appeared to be effective, increasing chest X-ray referrals and lung cancer diagnoses. This is an excellent example of identifying and responding to local health concerns in an innovative and effective way; it is a richly deserved winner of the Silver medal in the adult category.

The IPF field was rocked by the findings of the PANTHER trial, highlighted first in a Hot off the Breath article in Thorax. ${ }^{37}$ How could our treatment approach have been so spectacularly wrong for so long? We must ensure that this never happens again. To paraphrase St Paul, if I speak with the words of the wise, but have not solid evidence, I am a noisy gong or a clanging cymbal. However, the study does provide us with an opportunity to begin exploring other, potentially more fruitful treatment strategies. Proteasomal inhibition with Bortezomib ${ }^{38}$ and promotion of the effects of the death receptor ligand tumour necrosis factor-related apoptosisinducing ligand ${ }^{39}$ both look like promising approaches. Before embarking on clinical trials in IPF we need to be sure we use the most appropriate outcome measures. We agree with Athol Wells and colleagues ${ }^{40}$ that mortality should not be the be all and end all of these trials and that other patient centred and physiological endpoints still have a role. The King's brief interstitial lung disease health status questionnaire $^{41}$ and sarcoidosis questionnaire ${ }^{42}$ look potentially useful and the good old forced vital capacity holds up well as a marker of disease progression, whether expressed as a relative or absolute percentage change. ${ }^{43}$

New and existing measures of obstructive lung disease have been discussed in a number of papers. The use of the acute bronchodilator response has had a serious mauling in two studies evaluating this measure cross-sectionally and longitudinally in big populations. ${ }^{44}{ }^{45}$ When something can neither be measured repeatedly nor shown to relate to any important patient event, it's time to abandon it. There remains controversy about the best criteria for diagnosing chronic obstructive pulmonary disease (COPD), ${ }^{46-48}$ a debate that we suspect will never be resolved to everyone's satisfaction. Potentially new CT based measures ${ }^{49}$ might provide a fresh and important perspective as might novel blood and urine biomarkers. ${ }^{50} 51$ Previously promising markers of disease have had a bad year: Rinaldi et $a l^{52}$ failed to confirm a previous finding of antielastin antibodies in COPD although blood and urine desmosine, an elastin degradation product, has emerged as a promising biomarker. ${ }^{51}$ We suspect that the future is to view these measures as risk factors rather than arbitrary defining characteristics, as has been cogently pointed out by Guy Marks in a 'must read' opinion article. ${ }^{48}$ COPD lung attacks have been the focus of a number of excellent papers in 2012. Aaron et $a l^{53}$ suggested that attacks could be classified by their temporal pattern. Could these patterns be associated with different causes and treatment responses? Better risk stratification of patients presenting with an attack is an important priority, particularly if the current trend for devolving management to less specialised settings continues. We liked the Dyspnoea, Eosinopenia, Consolidation, Acidaemia and atrial Fibrillation score, ${ }^{54}$ developed after a realisation that existing scoring systems were inadequate, ${ }^{55}$ as it looks feasible, has good performance characteristics and benefits 
from a very catchy title (although to be critical, the editors at least maintain that coffee without caffeine is like a honeymoon without sex). The use of betablockers by patients with COPD was surprisingly shown to be associated with a trend to a better outcome in patients presenting with an attack $^{56}$ supporting the truth universally acknowledged (pace Jane Austen) that interventions that reduce heart rate improve life expectancy (and vice-versa; more on this in 2013). Otherwise it has been a quiet year for new treatments for obstructive lung disease with only small advances in prospect. ${ }^{57} 58$ A notable exception is the use of polymer sealant for lung volume reduction as, unlike endobronchial valves, efficacy appears to be independent of fissure integrity. ${ }^{59}$ Fissure integrity can be assessed directly by hyperpolarised gas $\mathrm{MRI}^{60}$ so potentially patients best suited for these different techniques can be identified. Our highlight, and the overwhelming winner of the gold medal in the adult category (and this award is not driven by pity at the disappointing medal haul of the Canadian Olympic team), is the paper by Suissa and colleagues $^{61}$ on the natural history of severe COPD lung attacks and mortality in a large community population. This team strike us as being the best sort of epidemiologists. They are not content with identifying marginal ORs of nebulous risk factors in poorly defined populations in studies with a high potential for confounding and, we suspect, have no desire to see their work featured in the Daily Mail. They ask important and highly clinically relevant question and provide answers that change the way we think about disease. Figure 3 of their paper should be seen and digested by all clinicians and health economists interested in chronic lung disease.

There have been a number of notable contributions in the sleep field. Whether obstructive sleep apnoea (OSA) is an independent risk factor for cardiovascular disease, insulin resistance and obesity have been hot questions for some time. In 2012 we learnt that, compared with controls, patients with OSA find it harder to lose weight and had a less complete metabolic response to a healthy eating and living initiative. $^{62}$ OSA was associated with increased levels of several coagulation factors, ${ }^{63}$ and an increased incidence of 'wake-up stroke'64 (a condition whose existence was news to us). On the other hand, two blinded appropriately controlled studies showed no evidence that treatment of OSA with continuous positive airway pressure (CPAP) improved markers of vascular risk. ${ }^{65} 66$ We liked particularly the Multicentre Obstructive Sleep Apnoea Interventional Cardiovascular Trial (MOSAIC) study ${ }^{65}$ and commend the study team for a sustained and impressive contribution to research in this area, which includes pioneering the use of sham CPAP treatment. They are our unanimous choice for the bronze medal. CPAP remains an effective treatment for sleepiness in OSA and other sleep related breathing disorders ${ }^{67}$ even if some of the effects can be explained by an expectation of benefit. ${ }^{68}$

We have quoted Hilaire Belloc before: 'Oh! Let no-one ever, ever doubt, What nobody is sure about' and 2012 has been a good year for doing just that. In our 2014 editorial address to the society, we will have a prize for the authors who have successfully toppled the most entrenched dogma, and also a WS Gilbert prize: 'On fire that glows With heat Intense I turn the hoe Of common sense And out it goes At small expense'. Finally, we will have a prize for the most ridiculous acronym smuggled into a serious article, following on from 'REPRINTED' and 'SCRAPPED'. ${ }^{69}$

\section{Competing interests None.}

Provenance and peer review Not commissioned; internally peer reviewed.

To cite Bush A, Pavord ID. Thorax 2013, 68, 1-4.

Accepted 5 November 2012

Thorax 2013;68:1-4.

doi:10.1136/thoraxjnl-2012-202970

\section{REFERENCES}

1 Mitchell EA, Beasley R, Keil U, et al. the ISAAC Phase Three Study Group. The association between tobacco and the risk of asthma, rhinoconjunctivitis and eczema in children and adolescents: analyses from Phase Three of the ISAAC programme. Thorax 2012;67:941-9.

2 Iskandar A, Andersen ZJ, Bønnelykke K, et al. Coarse and fine particles but not ultrafine particles in urban air trigger hospital admission for asthma in children. Thorax 2012;67:252-7.

3 Annesi-Maesano I, Hulin M, Lavaud F, et al. Poor air quality in classrooms related to asthma and rhinitis in primary schoolchildren of the French 6 Cities Study. Thorax 2012;67:682-8.

4 Scott M, Roberts G, Kurukulaaratchy RJ, et al. Multifaceted allergen avoidance during infancy reduces asthma during childhood with the effect persisting until age 18 years. Thorax 2012:67:1046-51.

5 Boyle RJ, Pedroletti C, Wickman M, et al., for the 4A Study Group. Nocturnal temperature controlled laminar airflow for treating atopic asthma: a randomised controlled trial. Thorax 2012;67:215-21.

6 Hales BJ, Chai LY, Elliot CE, et al. Original article: antibacterial antibody responses associated with the development of asthma in house dust mite-sensitised and non-sensitised children. Thorax 2012;67:321-7.

7 Turpeinen M, Pelkonen AS, Selroos 0 , et al. Continuous versus intermittent inhaled corticosteroid (budesonide) for mild persistent asthma in childrennot too much, not too little. Thorax 2012;67:100-2.

8 Feldman JM, Kutner $\mathrm{H}$, Matte $\mathrm{L}$, et al. Prediction of peak flows follwoed by feedback improves perception of lung function and adherence to inhaled corticosteroids in children with asthma. Thorax 2012;67:1040-5.

9 Fleming L, Wilson N, Regamey $\mathrm{N}$, et al. Use of sputum eosinophil counts to guide management in children with severe asthma. Thorax 2012;67:193-8.

10 Fleming L, Tsartsali L, Wilson N, et al. Sputum inflammatory phenotypes are not stable in children with asthma. Thorax 2012:67:675-81.

11 Pavord ID, Gibson PG. Inflammometry: the current state of play. Thorax 2012;67:191-2.

12 Green RH, Pavord I. Stability of inflammatory phenotypes in asthma. Thorax 2012;67:665-7.

13 Fleming L, Bush A. Use of sputum eosinophil counts to guide management in children with severe asthma. Thorax 2012;67:1015-16.

14 Pavord I, Gibson PG. Authors' response. Thorax 2012;67:1016

15 Vernooij-van Langen AMM, Loeber JG, Elvers B, et al. Novel strategies in newborn screening for cystic fibrosis: a prospective controlled study. Thorax 2012;67:289-95.

16 Mott LS, Park J, Murray CP, et al. on behalf of AREST CF. Progression of early structural lung disease in young children with cystic fibrosis assessed using CT. Thorax 2012;67:509-16.

17 Hoo A-H, Thia LP, Nguyen TTD, et al., on behalf of the London Cystic Fibrosis Collaboration (LCFC). Lung function is abnormal in 3-month-old infants with cystic fibrosis diagnosed by newborn screening Thorax 2012;67:874-81.

18 Ooi CY, Dupuis A, Ellis L, et al. Original article: comparing the American and European diagnostic guidelines for cystic fibrosis: same disease, different language? Thorax 2012;67:618-24.

19 Simmonds NJ, Bush A. Diagnosing cystic fibrosis: what are we sweating about? Thorax 2012;67: 571-3.

20 Stressmann FA, Rogers GB, van der Gast CJ, et al. Long-term cultivation-independent microbial diversity analysis demonstrates that bacterial communities infecting the adult cystic fibrosis lung show stability and resilience. Thorax 2012;67:867-73.

21 LiPuma J. The new microbiology of cystic fibrosis: it takes a community. Thorax 2012;67:851-2.

22 Hull J, Aniapravan R, Chan E, et al. British Thoracic Society guideline for respiratory management of children with neuromuscular weakness. Thorax 2012;67:i1-i40.

23 Hull J. Audit, research and guideline update: British Thoracic Society guideline for respiratory management of children with neuromuscular weakness: commentary. Thorax 2012;67:654-5.

24 Marchant J, Masters IB, Champion A, et al. Original article: randomised controlled trial of amoxycillinclavulanate in children with chronic wet cough. Thorax 2012;67:689-93.

25 Knowles MR, Leigh ML, Carson JL, et al., for the Genetic Disorders of Mucociliary Clearance Consortium. Mutations of DNAH11 in patients with primary ciliary dyskinesia with normal ciliary ultrastructure. Thorax 2012:67:433-41.

26 Knowles MR, Leigh MW, Zariwala MA. Cutting edge genetic studies in primary ciliary dyskinesia. Thorax 2012;67:464.

27 Hogg C, Bush A. Genotyping in primary ciliary dyskinesia: ready for prime time, or a fringe benefit? Thorax 2012:67:377-8.

28 Bush A, Hogg C. Authors' response. Thorax 2012:67:464.

29 Kotecha SJ, Watkins WJ, Paranjothy S, et al. Effect of late preterm birth on longitudinal lung spirometry in school age children and adolescents. Thorax 2012;67:54-61.

30 Saghir Z, Dirksen A, Ashraf H, et al. CT screening for lung cancer brings forward early disease. The randomised Danish Lung Cancer Screening Trial: status after five annual screening rounds with low-dose CT. Thorax 2012:67:296-301. 
31 Treasure T, Russell C, Morton D, et al. Surgical resection of lung cancer England: more operations but no trials to test their effectiveness. Thorax 2012;67:759-61.

32 Detterbeck FC. Cancer, concepts, cohorts and complexity: avoiding oversimplification of overdiagnosis. Thorax 2012;67:842-5.

33 Patel D, Akporobaro A, Chinyanganya N, et al. Attitudes to participation in a lung cancer screening trial: a qualitative study. Thorax 2012;67:418-25

34 Riaz SP, Linklater KM, Page R, et al. Recent trends in resection rates among non-small cell lung cancer patients in England. Thorax 2012;67:811-14.

35 Simon AE, Juszczyk D, Smyth $N$, et al. Knowledge of lung cancer symptoms and risk factors in the U.K.: development of a measure and results from a population-based survey. Thorax 2012;67:426-32.

36 Athey VL, Suckling RJ, Tod AM, et al. Early diagnosis of lung cancer: evaluation of a community-based social marketing intervention. Thorax 2012;67: 412-17.

37 McGrath EE, Millar AB. Hot off the breath: triple therapy for idiopathic pulmonary fibrosis-hear the PANTHER roar. Thorax 2012:67:97-8.

38 Mutlu GM, Budinger GR, Wu M, et al. Proteasomal inhibition after injury prevents fibrosis by modulating TGF-beta(1) signalling. Thorax 2012;67:139-46.

39 McGrath EE, Lawrie A, Marriott HM, et al. Deficiency of tumour necrosis factor-related apoptosis-inducing ligand exacerbates lung injury and fibrosis. Thorax 2012;67:796-803.

40 Wells AU, Behr J, Costabel U, et al. Hot of the breath: mortality as a primary end-point in IPF treatment trials: the best is the enemy of the good. Thorax 2012:67:938-40.

41 Patel AS, Siegert RJ, Brignall K, et al. The development and validation of the King's Brief Interstitial Lung Disease (K-BILD) health status questionnaire. Thorax 2012;67:804-10.

42 Patel AS, Siegert RJ, Creamer D, et al. The development and validation of the King's Sarcoidosis Questionnaire for the assessment of health status. Thorax Published Online First: 12 October 2012. doi:10.1136/thoraxjnl-2012-201962.

43 Richeldi L, Ryerson CJ, Lee JS, et al. Relative versus absolute change in forced vital capacity in idiopathic pulmonary fibrosis. Thorax 2012;67:407-11.

44 Albert P, Agusti A, Edwards L, et al. Bronchodilator responsiveness as a phenotypic characteristic of established chronic obstructive pulmonary disease. Thorax 2012:67:701-8.
45 Tan WC, Vollmer WM, Lamprecht B, et al. Worldwide patterns of bronchodilator responsiveness: results from the Burden of Obstructive Lung Disease study. Thorax 2012;67:718-26.

46 Jordan RE, Miller MR, Lam KB, et al. Sex, susceptibility to smoking and chronic obstructive pulmonary disease: the effect of different diagnostic criteria. Analysis of the Health Survey for England. Thorax 2012;67:600-5.

47 Brusasco V. Spirometric definition of COPD: exercise in futility or factual debate? Thorax 2012:67:569-70.

48 Marks GB. Are reference equations for spirometry an appropriate criterion for diagnosing disease and predicting prognosis? Thorax 2012;67:85-7.

49 Martinez $\mathrm{CH}$, Chen $\mathrm{YH}$, Westgate PM, et al. Relationship between quantitative CT metrics and health status and BODE in chronic obstructive pulmonary disease. Thorax 2012;67:399-406.

50 Takahashi T, Kobayashi S, Fujino N, et al. Increased circulating endothelial microparticles in COPD patients: a potential biomarker for COPD exacerbation susceptibility. Thorax 2012;67:1067-74.

51 Huang JT, Chaudhuri R, Albarbarawi 0, et al. Clinical validity of plasma and urinary desmosine as biomarkers for chronic obstructive pulmonary disease. Thorax 2012;67:502-8.

52 Rinaldi M, Lehouck A, Heulens N, et al. Antielastin B-cell and T-cell immunity in patients with chronic obstructive pulmonary disease. Thorax 2012:67:694-700.

53 Aaron SD, Donaldson GC, Whitmore GA, et al. Time course and pattern of COPD exacerbation onset. Thorax 2012;67:238-43.

54 Steer J, Gibson J, Bourke SC. The DECAF Score: predicting hospital mortality in exacerbations of chronic obstructive pulmonary disease. Thorax 2012:67:970-6.

55 Steer J, Norman EM, Afolabi OA, et al. Dyspnoea severity and pneumonia as predictors of in-hospital mortality and early readmission in acute exacerbations of COPD. Thorax 2012:67:117-21.

56 Stefan MS, Rothberg MB, Priya A, et al. Association between beta-blocker therapy and outcomes in patients hospitalised with acute exacerbations of chronic obstructive lung disease with underlying ischaemic heart disease, heart failure or hypertension. Thorax 2012;67:977-84.

57 Mahler DA, D'Urzo A, Bateman ED, et al. Concurrent use of indacaterol plus tiotropium in patients with COPD provides superior bronchodilation compared with tiotropium alone: a randomised, double-blind comparison. Thorax 2012;67:781-8.

58 Busse WW, Bleecker ER, Bateman ED, et al. Fluticasone furoate demonstrates efficacy in patients with asthma symptomatic on medium doses of inhaled corticosteroid therapy: an 8-week, randomised, placebo-controlled trial. Thorax 2012;67:35-41.

59 Magnussen $\mathrm{H}$, Kramer MR, Kirsten AM, et al. Effect of fissure integrity on lung volume reduction using a polymer sealant in advanced emphysema. Thorax 2012;67:302-8

60 Marshall H, Deppe MH, Parra-Robles J, et al. Direct visualisation of collateral ventilation in COPD with hyperpolarised gas MRI. Thorax 2012:67:613-17.

61 Suissa S, Dell'aniello S, Ernst P. Long-term natural history of chronic obstructive pulmonary disease: severe exacerbations and mortality. Thorax 2012;67:957-63.

62 Borel AL, Leblanc X, Almeras N, et al. Sleep apnoea attenuates the effects of a lifestyle intervention programme in men with visceral obesity. Thorax 2012;67:735-41.

63 Phillips CL, McEwen BJ, Morel-Kopp MC, et al. Effects of continuous positive airway pressure on coagulability in obstructive sleep apnoea: a randomised, placebo-controlled crossover study. Thorax 2012:67:639-44.

64 Ciccone A, Proserpio P, Roccatagliata DV, et al. Wake-up stroke and TIA due to paradoxical embolism during long obstructive sleep apnoeas: a cross-sectional study. Thorax 2012;67:1067-74.

65 Craig SE, Kohler M, Nicoll D, et al. Continuous positive airway pressure improves sleepiness but not calculated vascular risk in patients with minimally symptomatic obstructive sleep apnoea: the MOSAIC randomised controlled trial. Thorax 2012;67:1090-6.

66 Hoyos CM, Killick R, Yee BJ, et al. Cardiometabolic changes after continuous positive airway pressure for obstructive sleep apnoea: a randomised sham-controlled study. Thorax 2012;67:1081-9.

67 Ward NR, Cowie MR, Rosen SD, et al. Utility of overnight pulse oximetry and heart rate variability analysis to screen for sleep-disordered breathing in chronic heart failure. Thorax 2012;67:1000-5.

68 Crawford MR, Bartlett DJ, Coughlin SR, et al. The effect of continuous positive airway pressure usage on sleepiness in obstructive sleep apnoea: real effects or expectation of benefit? Thorax 2012;67: 920-4.

69 Furness JC. Correspondence: acronyms, pneumothoraces and the impact of international health on the NHS. Thorax 2012:67:833. 